\title{
Cloning and high-level production of a chitinase from Chromobacterium sp. and the role of conserved or nonconserved residues on its catalytic activity
}

\author{
Seur Kee Park • Chi Wook Kim • Hoon Kim • \\ Jae Sung Jung • G. E. Harman
}

Received: 22 May 2006 /Revised: 17 July 2006 / Accepted: 8 August 2006 / Published online: 9 February 2007

(C) Springer-Verlag 2007

\begin{abstract}
A gene encoding an alkaline (pI of 8.67) chitinase was cloned and sequenced from Chromobacterium sp. strain C-61. The gene was composed of 1,611 nucleotides and encoded a signal sequence of $26 \mathrm{~N}$-terminal amino acids and a mature protein of 510 amino acids. Two chitinases of 54 and $52 \mathrm{kDa}$ from both recombinant Escherichia coli and C-61 were detected on SDS-PAGE. Maximum chitinase activity was obtained in the culture supernatant of recombinant $E$. coli when cultivated in TB medium for 6 days at $37^{\circ} \mathrm{C}$ and was about fourfold higher than that from C-61. Chi54 from the culture supernatants could be purified by a single step based on isoelectric point. The purified Chi54 had about twofold higher binding affinity to chitin than to cellulose. The chis4 encoded a protein that included a type 3 chitin-binding domain
\end{abstract}

\author{
S. K. Park \\ Department of Agricultural Biology, \\ Sunchon National University, \\ Sunchon 540-742, South Korea \\ C. W. Kim \\ Technical Research Institute, Dong Bang Agro Corp., \\ Puyeo Gun 323-930, \\ ChungNam, South Korea \\ H. Kim \\ Department of Agricultural Chemistry, \\ Sunchon National University, \\ Sunchon 540-742, South Korea \\ J. S. Jung \\ Department of Biology, Sunchon National University, \\ Sunchon 540-742, South Korea \\ G. E. Harman $(\bowtie)$ \\ Department of Horticultural Sciences, Cornell University, \\ Geneva, NY 14456, USA \\ e-mail: geh3@cornell.edu
}

belonging to group A and a family 18 catalytic domain belonging to subfamily A. In the catalytic domain, mutation of perfectly conserved residues and highly conserved residues resulted in loss of nearly all activity, while mutation of nonconserved residues resulted in enzymes that retained activity. In this process, a mutant (T218S) was obtained that had about $133 \%$ of the activity of the wild type, based on comparison of $K_{\text {cat }}$ values.

Keywords Chitinase $\cdot$ Site-directed mutagenesis · Enzyme purification $\cdot$ Enzyme enhancement

\section{Introduction}

Chitinases (EC 3.2.1.14) hydrolyze the $\beta$-1,4-linkage of chitin, which is one of the most abundant natural polymers. Chitin is a major structural component of many arthropods and fungal cell walls (Flach et al. 1992). Most organisms produce chitinases including viruses, eubacteriales, archaebacteriales, fungi, and insects, as well as plants and vertebrates. Some enzymes may be useful in the control of agricultural pests, including enzymes with antifungal activity (Broadway et al. 1995; Chernin et al. 1995; Kobayashi et al. 2002; Lorito et al. 1993). Others with activity at alkaline $\mathrm{pH}$ values may degrade the peritrophic membranes that line insect guts. This affects insect digestion and is directly inhibitory to insect growth and development (Broadway et al. 1998) and may also increase susceptibility of insects to gut-active insecticides including the endotoxins from Bacillus thuringiensis (Ding et al. 1998) or baculoviruses (Shapiro et al. 1987). Such enzymes may be used directly in pest control strategies, or native or transgenic microbes that secrete potent enzyme mixtures can be employed as biocontrol agents (Fang et al. 2005). In 
addition, single or multiple genes may be expressed in plants, resulting in the control of diseases or herbivorous insects (Bolar et al. 2001; Ding et al. 1998).

We were interested in the discovery of chitinases that would possess activity against multiple plant pests. In earlier research, we isolated several chitinolytic bacteria from soil and identified the organisms with the greatest ability to solubilize chitin and that possessed strong biocontrol activity against plant pathogenic fungi. The bacterium with the highest chitinase production and biocontrol ability was identified as Chromobacterium sp. strain C-61 (Park et al. 1995a). A major chitinase from the bacterium had a molecular weight of $54 \mathrm{kDa}$ and a $\mathrm{pI}$ of 8.7 and played an important role in the biocontrol of plant pathogenic fungi (Park et al. 1995b,c). The chitinase was also stable in alkali pHs and so is likely to provide a significant tool for control of insect pests of plants.

Numerous chitinase genes have been cloned from a variety of organisms. There have been numerous attempts at the classification of enzymes based on sequence similarities. Chitinases are contained in families 18 and 19 of glycosyl hydrolases (Henrissat and Davies 1997) and most bacterial chitinases, except for chitinases of Streptomyces spp. and actinobacteria (Kawase et al. 2004), belong to family 18 and contain a catalytic domain plus, in most cases, a chitinbinding domain (http://smart.embl-heidelberg.de). Chitinbinding domains of bacterial chitinases were primarily of type 3 (Henrissat 1999), which has been further subdivided (Hashimoto et al. 2000).

In this study, a gene encoding a major chitinase (Chi54) from Chromobacterium sp. strain C-61 was cloned. Moreover, the various domains that provide functionality were identified and site-directed mutagenesis was used to identify essential functional amino acids within the catalytic domains. This provided a basis for improvements in activity, and one mutant indeed possessed higher activity than the original strain. In addition, methods for rapid production of the modified or functional pure proteins were identified.

\section{Materials and methods}

Bacterial strains, plasmids, and culture conditions

Chromobacterium sp. strain C-61 was grown in nutrient broth (NB, Difco, Detroit) containing $50 \mu \mathrm{g} / \mathrm{ml}$ of ampicillin at $28^{\circ} \mathrm{C}$. Escherichia coli XL1-Blue MRF' (Stratagene, La Jolla, CA) was used for the construction of the ZAP express library amplification of phage clones and the expression of the pBK phagemids. E. coli strains were grown at $37^{\circ} \mathrm{C}$ on Luria-Bertani (LB) medium (Sambrook et al. 1989) supplemented with $50 \mu \mathrm{g} / \mathrm{ml}$ of kanamycin where necessary and with $0.2 \%$ maltose and
$10 \mathrm{mM} \mathrm{MgSO}_{4}$ for the propagation of lambda phages. Strain C-61 is deposited in the Korean Agricultural Culture Collection (National Institute of Agricultural Biotechnology, Suwon, Republic of Korea, http://wdcm.nig.ac.jp/ CCINFO/CCINFO.xml?806) as accession KACC 91199P.

Construction of a genomic library and screening of chitinase-producing clones

Chromosomal DNA of Chromobacterium sp. strain C-61 was partially digested with Sau3A1 and ligated into the BamHI site of the ZAP Expression vector (Stratagene). The ligation mixtures were packaged into phage particles using Gigapack III Gold packaging extract (Stratagene) and then amplified in E. coli XL1-Blue MRF' cells. The phages were plated and transferred to nitrocellulose membranes soaked with $10 \mathrm{mM}$ isopropyl- $\beta$-D-thiogalactopyranoside (IPTG) to induce the lac promoter. The nitrocellulose membranes were hybridized with the anti-chitinase sera using picoBlue Immunoscreening Kit (Stratagene). Polyclonal antibodies were produced in female mice by immunization with $75 \mu \mathrm{g}$ of purified chitinase (A \& PEP, Chungnam, South Korea). Specificity and titer of the antibodies were evaluated by dot blot test and agar-double diffusion test. Phages of hybridized plaques were cultured in LB broth containing E. coli and the culture solutions were tested for chitinase activity by release of 4-methylumbelliferyl- $\beta-D-N, N^{\prime}$-diacetylchitobioside [designated 4-MU-(GlcNAc) $)_{2}$ hereafter] (Sigma, St. Louis, MO). The chitinase-producing phages were incubated with the Exassist helper phages and E. coli XL1-Blue MRF' cells to excise the $\mathrm{pBK}-\mathrm{CMV}$ phagemid vector from the ZAP Express vector. The excised phagemids containing the cloned insert were use to transfect $E$. coli XLOLR, which prevents replication of the helper phage genome and lambda DNA contamination. Colonies were selected that cleared colloidal chitin on 1/2 strength LB medium.

DNA sequencing and analysis

DNA sequencing was performed on an Applied Biosystems Automated 3730 DNA Analyzer with Big Dye Terminator chemistry and AmpliTaq-FS DNA Polymerase at the Cornell Biotechnology Resource Center (http://www.brc.cornell.edu/brcinfo/index.php?f=1). Homology searches in GenBank were carried out in Protein-protein BLAST (blastp) at NCBI (http://www.ncbi. nlm.nih.gov/BLAST/). The predicted molecular weight and $\mathrm{pI}$ value of the chitinase were calculated using Compute pI/Mw (http://us.expasy.org/tools/pi tool.html). The predicted signal sequence was identified with SignalP (http://www.cbs.dtu.dk/services/SignalP). The predicted domains were located with the SMART program (http://smart.embl-heidelberg.de). 
Subcloning of an open reading frame (ORF) containing a chitinase gene

One insert in pBK-CMV consisted of 3,787 bp that included 3,690 bp from strain C-61 and $97 \mathrm{bp}$ of vector DNA. An ORF of the chitinase gene was located in 11,787 bp and an ApaI site was located at 1,846 bp and another at 3,744 bp (vector DNA region) within the recombinant plasmid. DNA of about $6.3 \mathrm{~kb}$ containing pBK-CMV (about $4.5 \mathrm{~kb}$ ) and the chitinase gene $(1,846 \mathrm{bp})$ was extracted using agarase (Roche, Mannheim, Germany) from gels. After digestion with ApaI, the extracted DNAs were ligated and transformed into E. coli XL1-Blue MRF'. Transformants expressing the enzyme were identified by formation of clearing zones on chitin agar plates, thereby selecting for the DNA segment that contained the gene.

\section{Site-directed mutagenesis of Chi54}

Site-specific mutations were conducted using QuikChange site-directed mutagenesis kit (Stratagene). The oligonucleotide primers used for mutagenesis are shown in Table 1. The vectors containing chi54 were PCR-amplified using
$P f u$ DNA polymerase according to the manufacturer's protocol. The product was then treated with $D p n I$ endonuclease, specific for methylated and hemimethylated DNA to digest the C-61 DNA template. The vector DNA carrying the desired mutations was transformed and proliferated in E. coli XL1-Blue supercompetent cells. The candidate clones were selected by size of clearing zone on 1/2 LB plates containing colloidal chitin. The mutant clones were confirmed by sequencing of the inserted DNA.

\section{Production of Chi54 and mutated Chi54}

The chitinolytic ability of strain C-61 and E. coli carrying a chi54 or mutated chi54 was first compared by sizes of halos on $1 / 2$ strength LB medium containing $0.1 \%$ colloidal chitin after 5 days incubation at 30 or $37^{\circ} \mathrm{C}$. To determine the optimum culture conditions of recombinant $E$. coli on chitinase production, growth of a single colony was initiated by shaking overnight and $500 \mu \mathrm{l}$ was inoculated into $50 \mathrm{ml} \mathrm{LB}$ or Terrific Broth (TB) (Sambrook et al. 1989) containing kanamycin in a $250 \mathrm{ml}$ flask. The culture was incubated with shaking at $37^{\circ} \mathrm{C}$ until $\mathrm{OD}_{600}$ reached 0.6 (about 5-6 h culture). Subsequently, $500 \mu \mathrm{l}$ of $100 \mathrm{mM}$
Table 1 Primers used for sitedirected mutagenesis of the nucleotides encoding the catalytic sites of Chi54

\begin{tabular}{|c|c|c|}
\hline \multicolumn{2}{|c|}{ Mutated Sites } & \multirow[t]{2}{*}{ Primer $^{\mathrm{a}}$} \\
\hline Regions & Amino acid change & \\
\hline \multirow[t]{8}{*}{$\overline{\beta 3}$} & $\mathrm{~S} 213 \mathrm{E}^{\mathrm{b}}$ & Forward 5'-CTGAAAGTGCTGATTGAACTGGGCGGCTGGACC-3 \\
\hline & & Reverse 5'-GGTCCAGCCGCCCAGTTCAATCAGCACTTTCAG-3' \\
\hline & $\mathrm{G} 215 \mathrm{E}$ & 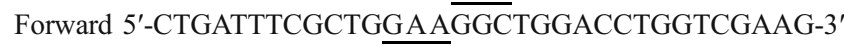 \\
\hline & & Reverse 5'-CTTCGACCAGGTCCAGCCTTCCAGCGAAATCAG-3' \\
\hline & $\mathrm{G} 216 \mathrm{E}$ & Forward 5'-CTGATTTCGCTGGGCGAATGGACCTGGTCGAAG-3' \\
\hline & & Reverse 5'-CTTCGACCAGGTCCATTCGCCCAGCGAAATCAG-3' \\
\hline & $\mathrm{T} 218 \mathrm{~S}$ & 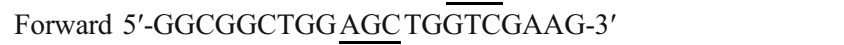 \\
\hline & & Reverse 5'-CTTCGACCAGCTCCAGCCGCC-3' \\
\hline \multirow[t]{8}{*}{$\beta 4$} & $\mathrm{I} 270 \mathrm{~L}$ & Forward 5'-GGCATCGAC $\overline{C T G G A C T G G G A A T A C-3 ' ~}$ \\
\hline & & Reverse 5'-GTATTCCCAGTCC AGGTCGATGCC-3' \\
\hline & $\mathrm{I} 270 \mathrm{~V}$ & 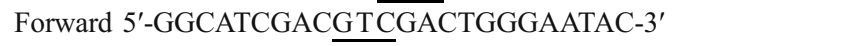 \\
\hline & & Reverse 5'-GTATTCCCAGTCGACGTCGATGCC-3' \\
\hline & D271W & Forward 5'-CATCGACATCTGGTGGGAATACC-3' \\
\hline & & 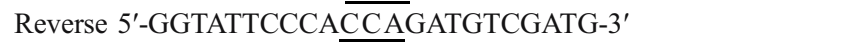 \\
\hline & E273W & Forward 5'-GACATCGACTGGTGGTACCCGGGCGGC-3' \\
\hline & & 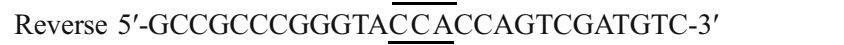 \\
\hline \multirow[t]{4}{*}{$\beta 7$} & N401V & Forward 5'-GACCAAGCTGGTCGTGGGCATC-3' \\
\hline & & Reverse 5'-GATGCCCACG $\overline{A C C A G C T T G G T C-3 ' ~}$ \\
\hline & G403E & Forward 5'-GCTGAACGTGGAAATCCCGTTCT-3' \\
\hline & & Reverse 5'-AGAACGGGATTTCCACGTTCAGC-3' \\
\hline \multirow[t]{8}{*}{$\beta 8$} & G492E & Forward 5'-CAACAGCTGGGCGAAGTGTTCAGCTGG-3' \\
\hline & & 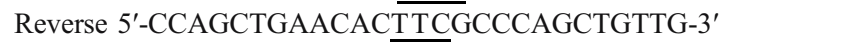 \\
\hline & V493M & Forward 5'-CTGGGCGGGATGTTCAGCTGGTC-3' \\
\hline & & Reverse 5'-GACCAGCTG $\overline{A A C}$ ATCCCGCCCAG-3' \\
\hline & W496E & 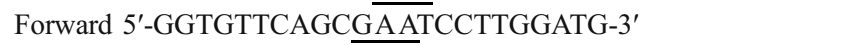 \\
\hline & & Reverse 5'-CATCCAAGGATTCGCTGAACACC-3' \\
\hline & S497E & Forward 5'-GTTCAGCTGGGAGTTGGATGGCGA-3' \\
\hline & & Reverse 5'-TCGCCATCCAAC $\overline{\overline{C T C} C C A G C T G A A C-3^{\prime}}$ \\
\hline
\end{tabular}

\footnotetext{
${ }^{a}$ Underlined codons indicate the nucleotide changes made using the QuikChange site-directed mutagenesis kit and confirmed by sequencing.

${ }^{\mathrm{b}}$ The change in amino acid is indicated by the numberletter combinations and the region indicates the strand of the catalytic domain in which the mutation was made, see Figs. 4 and 7.
} 
IPTG was added or not added to the culture broth and culture was continued. At various times, the $\mathrm{OD}_{600}$ of the culture broth was measured to determine cell growth and chitinase activity was determined with the culture supernatant. The chitinase activities of the wild-type and mutants were compared with culture supernatant and cytoplasmic extracts. Their cytoplasmic extracts were obtained from cells cultured in $\mathrm{TB}$ at $37^{\circ} \mathrm{C}$ for 1 day as described in the pET system manual (Novagen, Darmstadt, Germany), and culture supernatants were obtained after 5 days incubation at $37^{\circ} \mathrm{C}$ in $1 / 2 \mathrm{LB}$ containing colloidal chitin.

\section{Purification of Chi54 and mutated Chi54}

The chitinases were purified from culture supernatant of $E$. coli strains grown for 4 days at $37^{\circ} \mathrm{C}$ in $1 / 2 \mathrm{LB}$ containing colloidal chitin. The culture supernatants $(300 \mathrm{ml})$ were precipitated with solid ammonium sulfate, dissolved in $6 \mathrm{ml}$ of $20 \mathrm{mM}$ sodium acetate buffer ( $\mathrm{pH}$ 6.0) and desalted by dialysis. The proteins were mixed with $1.2 \mathrm{ml}$ of $40 \%$ ampholytes (pH 3-10) and with $10.8 \mathrm{ml}$ of deionized water. The samples were loaded in a Mini Rotofor chamber (BioRad, Hercules, California) and run at $12 \mathrm{~W}$ constant power for $4 \mathrm{~h}$ with $0.1 \mathrm{M} \mathrm{H}_{3} \mathrm{PO}_{4}$ at the anode and $0.1 \mathrm{M} \mathrm{NaOH}$ at the cathode. After harvesting, the fractions containing chitinases were pooled and dialyzed, and then analyzed by sodium dodecyl sulfate-polyacrylamide gel electrophoresis (SDS-PAGE). The protein concentration was measured with a protein assay kit (Bio-Rad) with bovine serum albumin as a standard.

\section{Enzyme activity assays}

Activity of the enzyme was assayed against 4-MU$(\text { GlcNAc) })_{2}$, colloidal chitin or crystal chitin (Sigma, C8908). Assays for 4-MU-(GlcNAc) $)_{2}$ were conducted in $100 \mu \mathrm{l}$ of a mixture containing $0.1 \mathrm{mM}$ substrate and enzyme in $100 \mathrm{mM} \mathrm{KH}{ }_{2} \mathrm{PO}_{4}+\mathrm{NaOH}$ buffer ( $\mathrm{pH}$ 7.0). After incubation for $10 \mathrm{~min}$ at $37^{\circ} \mathrm{C}$, the reaction was stopped by addition of $0.1 \mathrm{ml}$ of $0.2 \mathrm{M} \mathrm{Na}_{2} \mathrm{CO}_{3}$ and measured with an excitation at $360 \mathrm{~nm}$ and an emission at $440 \mathrm{~nm}$ on a BioTek FLx800 (BioTek, Vermont, USA). One unit of chitinase activity was expressed as micromoles of liberated 4-methylumbelliferone per min. Assays for determination of kinetic constants were conducted at concentrations of 4$\mathrm{MU}-(\mathrm{GlcNAc})_{2}$ ranging from 2.5 to $100 \mu \mathrm{M}$. The initial rate of hydrolysis was determined for each assay. $K_{\mathrm{m}}$ and $K_{\text {cat }}$ were calculated from an average of three experiments by the Michaelis-Menten equation.

Colloidal chitin was prepared from native chitin (Sigma, C9213) (Jeuniaux 1966). Assays for colloidal chitin and native chitin were reacted in a mixture $(1.0 \mathrm{ml})$ containing $0.5 \%(\mathrm{w} / \mathrm{v})$ substrates and enzyme in $100 \mathrm{mM} \mathrm{KH}_{2} \mathrm{PO}_{4}+$
$\mathrm{NaOH}$ buffer (pH 7.0). After incubation for $30 \mathrm{~min}$ at $37^{\circ} \mathrm{C}$, the reaction was stopped by boiling for $5 \mathrm{~min}$. A mixture containing $200 \mu \mathrm{l}$ supernatant solution after centrifugation and $260 \mu \mathrm{l}$ color reagent solution $(0.05 \%$ potassium ferricyanide in $0.5 \mathrm{M} \mathrm{Na}_{2} \mathrm{CO}_{3}$ ) was boiled for $15 \mathrm{~min}$. The reaction mixtures $(100 \mu \mathrm{l})$ were transferred to a 96well microtiter plate and measured at $420 \mathrm{~nm}$ on a BioTek $\mu$ Quant (BioTek). One unit of chitinase activity against colloidal chitin and native chitin was expressed as micromoles of liberated $\mathrm{N}$-acetylglucosamine per min per mg of purified chitinase.

Polysaccharide binding assay

Qualitative evaluation of binding capacity was conducted with cytoplasmic extracts of recombinant $E$. coli by a modification of the procedures described in Simpson et al. (Simpson et al. 2000). Protein $(100 \mu \mathrm{g})$ of cytoplasmic extracts was incubated with $50 \mathrm{mg}$ of purified chitin (Sigma) or Avicel PH-101 (Fluka [from Sigma]) in $20 \mathrm{mM}$ Tris- $\mathrm{HCl}$ buffer $\mathrm{pH} 7.5$ in a total volume of $400 \mu \mathrm{l}$. After $1 \mathrm{~h}$ on ice with gentle mixing, supernatants and pellets were separated by centrifugation. The pellets were washed two times with $20 \mathrm{mM}$ Tris- $\mathrm{HCl}$ buffer ( $\mathrm{pH}$ 7.5), and then the bound protein was eluted by boiling for $10 \mathrm{~min}$ in $100 \mu \mathrm{l}$ of $10 \%(\mathrm{w} / \mathrm{v})$ SDS. The samples $(20 \mu \mathrm{l})$ were subjected to SDS-PAGE. Quantitative evaluation of binding capacity was conducted with purified enzymes. The reaction mixtures $(400 \mu \mathrm{l})$ containing $50 \mu \mathrm{g}$ of protein and $12.5 \mathrm{mg}$ of polysaccharides in $20 \mathrm{mM}$ Tris- $\mathrm{HCl}$ buffer $(\mathrm{pH}$ 7.5) were incubated for $1 \mathrm{~h}$ on ice with gentle mixing. After centrifugation, protein concentration in the supernatant was measured with a protein assay kit (Bio-Rad).

Detection of chitinolytic enzymes after gel electrophoresis

Discontinuous SDS-PAGE was performed by the method of Laemmli (1970) in 10\% polyacrylamide gels. Samples were mixed with an equal volume of $30 \%(\mathrm{w} / \mathrm{v})$ sucrose, $5.0 \%$ $(\mathrm{w} / \mathrm{v}) \mathrm{SDS}$ in $250 \mathrm{mM}$ Tris- $\mathrm{HCl}(\mathrm{pH} 6.8)$ and $0.02 \%(\mathrm{w} / \mathrm{v})$ bromophenol blue without 2-mercaptoethanol. After electrophoresis, the enzymes were reactivated by removing SDS using the casein-EDTA procedure (McGrew and Green 1990), and their activities were detected on the gels by using 4-MU-(GlcNAc) $)_{2}$ (Tronsmo and Harman 1993).

The chitinolytic bands of $E$. coli strains expressing chi54 or mutated chi54 genes were compared by the method of Trudel and Asselin (1989) because it is more sensitive than the methylumbelliferyl assays. In this case, SDS-PAGE was conducted on gels containing $0.01 \%$ glycol chitin. The gel was incubated at $37^{\circ} \mathrm{C}$ for $3 \mathrm{~h}$ with slow shaking in $100 \mathrm{mM}$ sodium acetate buffer, $\mathrm{pH}$ 5.0, containing $1 \%(\mathrm{w} / \mathrm{v})$ Triton X-100 and then stained with $0.01 \%(\mathrm{w} / \mathrm{v})$ Calcofluor White 
M2R (Sigma, F6259) in $500 \mathrm{mM}$ Tris- $\mathrm{HCl}, \mathrm{pH} 8.9$, for $5 \mathrm{~min}$. After destaining by soaking for at least $1 \mathrm{~h}$ at room temperature in distilled water, lytic zones were observed under the UV-transilluminator. Proteins separated by SDSPAGE were stained with silver nitrate and their molecular weights were determined by comparison with Silver Stain SDS-PAGE standards, low range (Bio-Rad).

\section{Results}

Cloning of a chitinase gene and overexpression in E. coli

Two clones from the recombinant phage library hybridized to antiserum were prepared against chitinase purified from Chromobacterium and secreted chitinase (methylumbelliferone assay). These were amplified, converted into phagemids (pBK-CMV), and transfected into E. coli XLOLR. The recombinant strains formed clearing zones on media containing colloidal chitin. The smaller insert DNA consisted of 3,690 nucleotides, which contained three ORFs. The plasmid from pBK-CMV containing an ORF of the chitinase gene (1,846 bps) was transformed into E. coli XL1-Blue MRF' (Stratagene). The chitinase gene was named chi54 and the protein it encodes was designated Chi54.

The nucleotide sequence of chi54 and its deduced amino acid sequence are available as GenBank accession AY263367. The potential ribosome-binding sequence, 5'AGGAGG-3', began $11 \mathrm{nt}$ upstream of the start codon (ATG). An inverted repeat 5'-CCGCCGGGCATGCCCGGCGG-3' began $26 \mathrm{nt}$ downstream of the terminal codon (TAA). The ORF consists of 1,611 nucleotides encoding 536 amino acids. A putative signal sequence of 26 amino acids was present with a predicted cleavage site after A26. The deduced mature protein (510 aa) was calculated to have a molecular weight of $55,102 \mathrm{Da}$ and $\mathrm{pI}$ value of 8.67 .

The E. coli harboring chi54 (strain Chi54-0) formed a larger clearing zone than that of strain C-61 after 5 days growth at $37^{\circ} \mathrm{C}$ (Fig. 1a). However, at $30^{\circ} \mathrm{C}$ the sizes of the clearing zones from strain Chi54-0 or strain C-61 were similar (Fig. 1b). The culture supernatant of strain Chi54-0 showed two chitinases with molecular weights of about 54 and $52 \mathrm{kDa}$ after SDS-PAGE. These were very similar to some of the chitinases produced by strain C-61 (Fig. 1c).

To compare the level of chitinase production from strain C-61 and strain Chi54-0, the conditions for their maximal production were investigated. Chitinase production and the cell growth of strain Chi54-0 were much better in TB medium than in LB medium (Fig. 2). Maximum chitinase levels were obtained after 5 days of cultivation in LB medium and 6 days of cultivation in TB medium (Fig. 2b). The cell density decreased after 8 days of cultivation in LB medium, but continuously increased through 10 days of

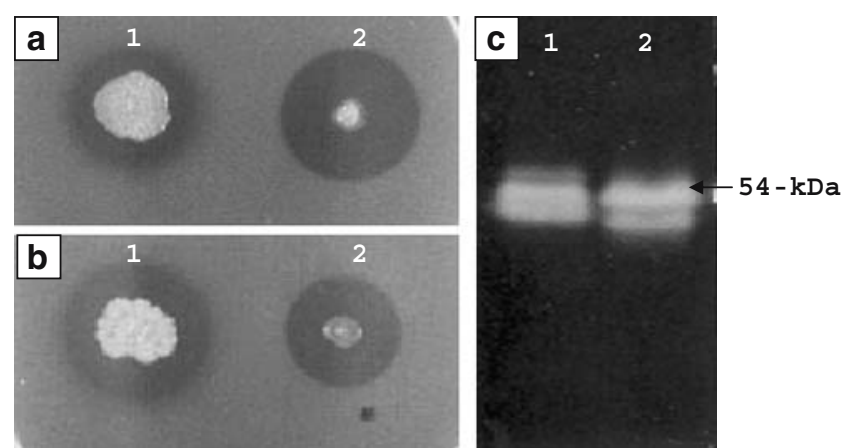

Fig. 1 Chitinolytic ability of Chromobacterium sp. strain C-61 (1) and recombinant $E$. coli (2) on $1 / 2$ LB plates containing colloidal chitin $(\mathbf{a}, \mathbf{b})$ and their chitinolytic proteins after SDS-PAGE (c). a was incubated at $37^{\circ} \mathrm{C}$ and $\mathbf{b}$ was incubated at $30^{\circ} \mathrm{C}$ for 5 days

cultivation in TB medium (Fig. 2a). The addition of IPTG resulted in slightly increased chitinase production in both TB and LB medium (Fig. 2b). In a previous study (Park et al. 1995b), the highest levels of chitinase production from strain C-61 was in minimal medium containing colloidal chitin and the greatest level of enzyme activity was obtained after 4 days of cultivation at $28^{\circ} \mathrm{C}$. The chitinase activities of culture supernatants obtained from these optimized conditions were $11.9 \mathrm{U} / \mathrm{ml}$ in strain Chi54-0 and $3.0 \mathrm{U} / \mathrm{ml}$ in strain C-61. This result indicates that strain Chi54-0 can produce about fourfold more chitinase than strain C-61 under optimal growth conditions for the two organisms.

Binding affinity of Chi54 to polysaccharides

Binding of Chi54 to chitin and cellulose (Avicel) was first identified by SDS-PAGE. The Chi54 bound to both chitin and cellulose, but its binding affinity was greater on chitin than on cellulose (Fig. 3a). This was further examined with purified enzymes. The Chi54 had about twofold higher binding affinity to chitin than to cellulose (Fig. 3b).

\section{Domain structures of Chi54}

The mature protein was predicted to have a chitin-binding domain type 3 (ChtBD3, aa 30 to 74), a segment of low compositional complexity (aa 80 to 103), a family 18 catalytic domain (CatD, aa 104 to 501) and another segment of low compositional complexity (aa 518 to 533), as determined using the SMART program (http:// smart.embl-heidelberg.de/) (Fig. 4). The ChtBD3s of Chi54 and other bacterial chitinases in the CHROMA format of SMART program were further aligned on the basis of sequence alignments of Brun et al. (1997), Ikegami et al. (2000), and Hashimoto et al. (2000). The ChtBD3s were 
a

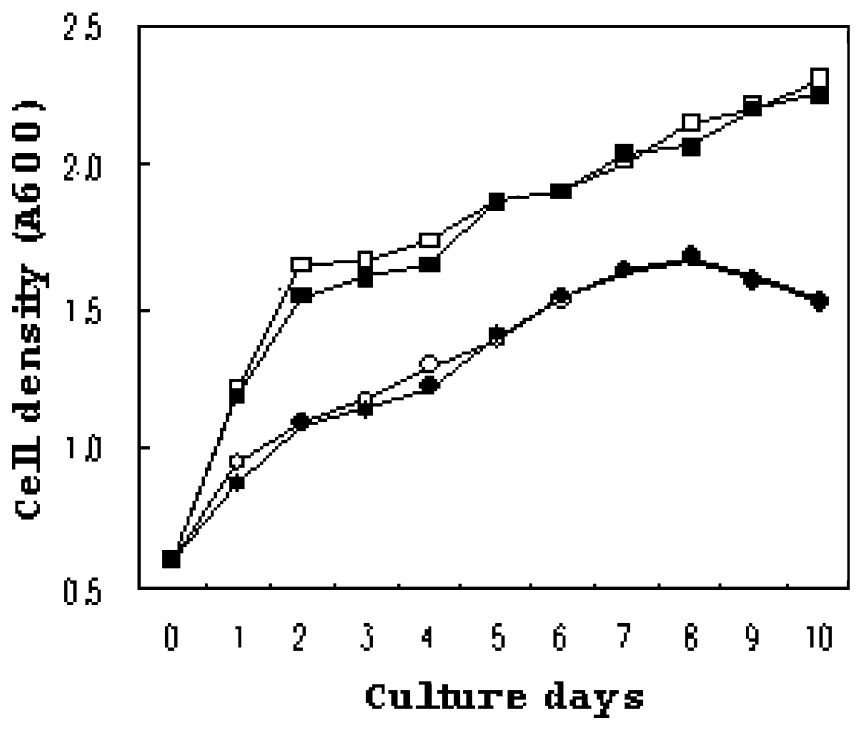

Fig. 2 Cell growth (a) and extracellular chitinase activity (b) of recombinant $E$. coli. Cells were grown in $\mathrm{LB}$ and $\mathrm{TB}$ media at $37^{\circ} \mathrm{C}$ with shaking, and the IPTG was added to cultures with $\mathrm{OD}_{600}=0.6$. At various time points after adding the IPTG, the cell density was measured by determining the $\mathrm{OD}_{600}$. The activity in the culture supernatants was measured with $4-\mathrm{MU}-(\mathrm{GlcNAc})_{2}$ in $100 \mathrm{mM}$ $\mathrm{KH}_{2} \mathrm{PO}_{4}+\mathrm{NaOH}$ buffer $(\mathrm{pH} 7.0)$ for $10 \mathrm{~min}$ at $37^{\circ} \mathrm{C}$ as described in

classified into group A with a stWWst motif (s stands for small and t for turn-like residue (Brun et al. (1997)) and group B without the motif, but all of them possessed four aromatic residues, $\mathrm{W}(\mathrm{Y}), \mathrm{Y}, \mathrm{W}(\mathrm{Y})$ and $\mathrm{W}(\mathrm{Y})$, and an amino residue, $\mathrm{P}$, as conserved residues. The ChtBD3 of Chi54 was contained in group A. Of the members in the group A, $\mathrm{CBD}_{\mathrm{EGZ}}$ possessed a DWAGGQ loop, but lacked an aromatic residue $(\mathrm{Y})$ conserved in all other ChtBD3s analyzed. Chitinase B from Serratia marcescens and a few other chitinases had a single aromatic residue (W) in the position of the stWWst motif (Fig. 5). b

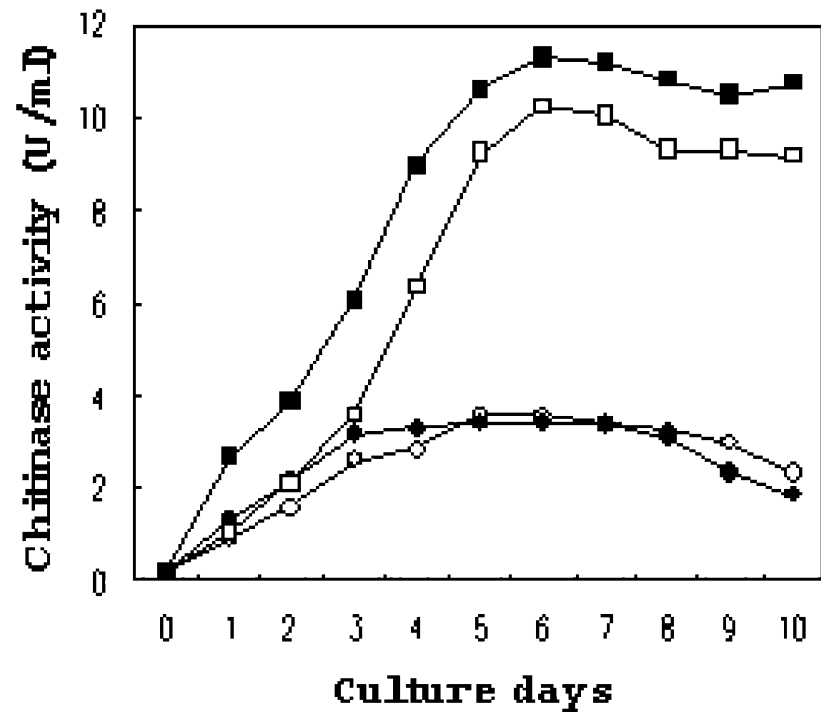

the Materials and methods section. The activity (U/ml culture supernatant) was expressed as micromoles of liberated 4-methylumbelliferone per minute. Each value represents the mean of three separate determinations. Symbols: open circles (०),-IPTG in LB; filled circles $(\bullet),+\mathrm{IPTG}$ in LB; open squares $(\square),-\mathrm{IPTG}$ in TB; filled squares $(\boldsymbol{\bullet}),+$ IPTG in TB

A segment of low compositional complexity (aa 80 to 103) that was located between a ChtBD and a CatD region of Chi54 was a proline-rich region (TPGGGDPGPGPGTG VPPEPTPTVG) (Fig. 4). This region was considered to play a role as linker because repeats of proline and hydroxyamino acids (residues 98 to 101) have been reported as linker regions between discrete functional domains in a number of polysaccharidases (Gilkes et al. 1991). The amino acid residues 518 to 533 (AAAAKKKAAAKTSAAS) of Chi54 (Fig. 4) did not match other bacterial chitinases but was similar to basic proteins when examined with short, nearly exact matches in BLAST.
Fig. 3 Polysaccharide-binding capacities. a Qualitative binding of crude Chi54. Lane 1, proteins from cytoplasm; lanes 2 and 3 , proteins unbound and bound, respectively, in chitin; lanes 4 and 5 ; proteins unbound and bound, respectively, in cellulose (Avicel). b Quantitative binding of purified Chi54. The purified protein $(50 \mu \mathrm{g})$ was incubated with $12.5 \mathrm{mg}$ of chitin or cellulose for $1 \mathrm{~h}$ on ice. The amount of protein in the supernatant (unbound protein) is shown
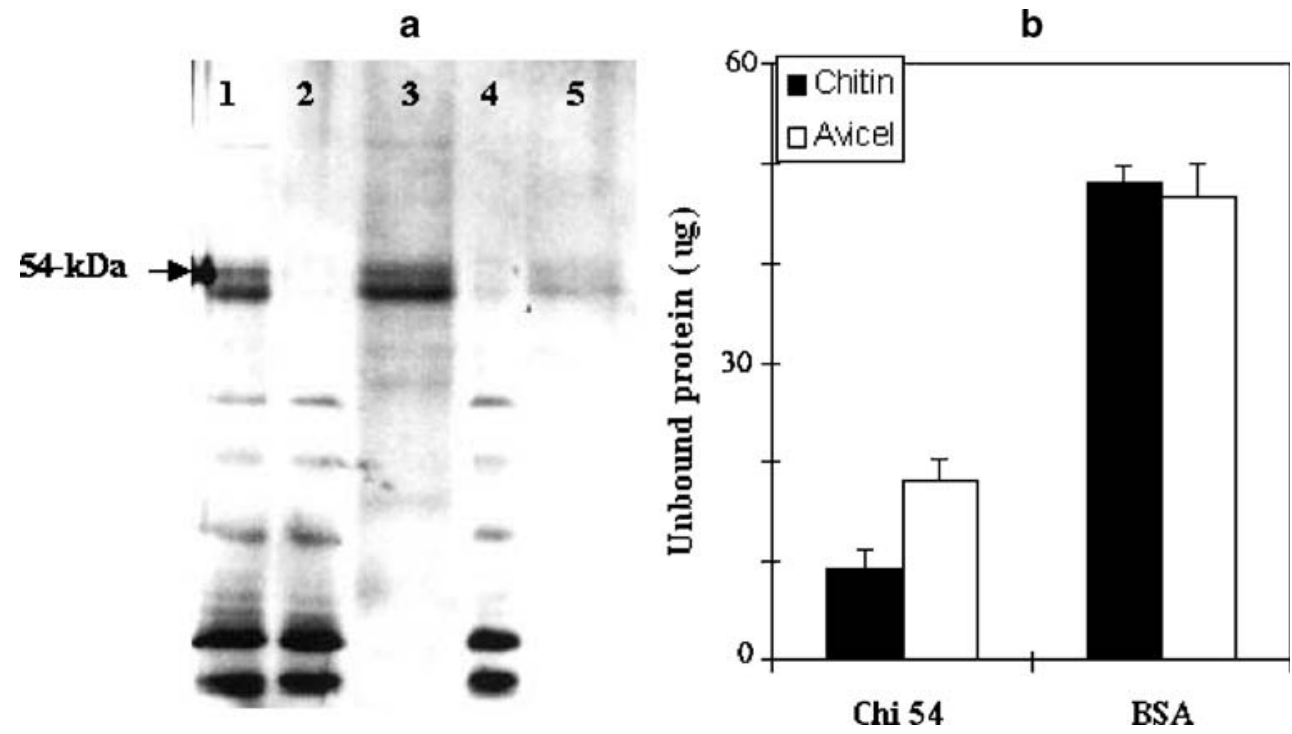
1 aagctggagctcgcgcgcctgcaggtcgacactagtggatcactgacagaattgagaggtccgaatgtcgaaactttcgttgacgttgtcggcgctgt $\begin{array}{llllllllllllllll}M & S & K & L & S & L & T & L & S & A & L\end{array}$

100 ttggaggggctggcttgttgttgagcagcgcggcggcgttcgccgcgccggcetgcagcgcgtggagcaatgcgcagacctataacggcggcgattacg

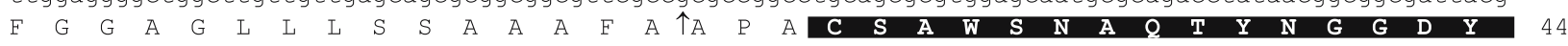

199 ccttgtacgccaacaagacctggcgcgccaagtggtggacgcagaacaatcagccgggcgcggatcaatggggaccgtgggaggagaggccggctagcg

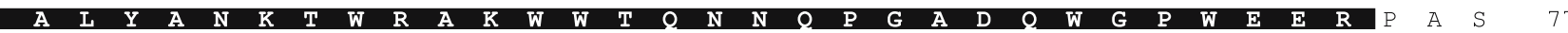

298 aatgcaccccgggcggcggcgaccccggccccgggccgggcacgggcgtgcctcccgagccgacgccgacggtgggccgccatgttggttcctattttg

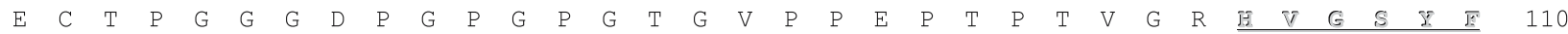

397 cgcaatggagcatttacggccgtaattacaagctgcgcaatctggtggatgccggcggcgacaagaagctgaccttcctgaactacgctttcggcaatg

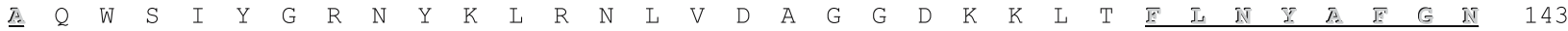

496 tctacgccgacggcaatgcggcatggtgacccgcgccgagaacggcaacggcgacggcggcgacgcctgggcggactaccagaaatccttcggcgcca

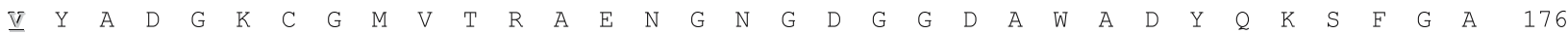

595 atgagtcggtggacggcaaggccgatagctggagcgacccgctgcgcggcaacttcaatcagctgcgcaagctgaagctggccaatccctcgctgaaag

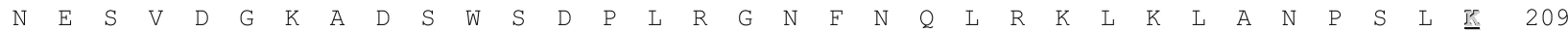

694 tgctgatttcgctgggcggctggacctggtcgaagaatttcggcaagttcgccgccaccgacgctggccgcaagaccatggtggcgtcctgcatcgatc

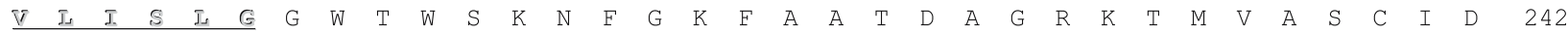

793 tgtacctgaaaggcaatctgccggtgggcgagaacgccggcggcgccggcgcggccaagggagtgttcgacggcatcgacatcgactgggaatacccgg

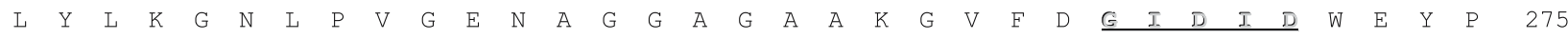

892 gcggcggcggcctgccgagcaatagcgtggatcccaacgacaagcagaacttcaccttgctgatggcggagttccgcagccagctggacgcgctgaccg

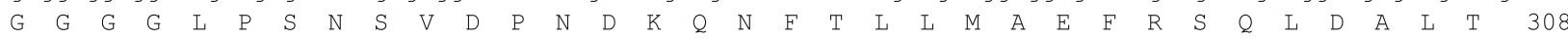

991 cgcagaacaagcgccgctactacctgaccgcggcgatcggctccggcgtcgacaagatccgccagaccgagccggccaagtacgcggcctacatggact

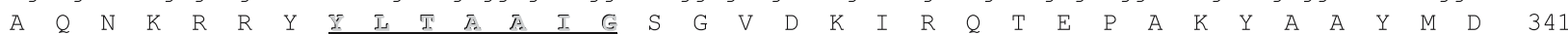

1090 ggatcaatgtgatgacctacgacttcaacggcggctgggacgcaaaagggccgaccaacttccagtccaatctgttccgcgatccggccgctccggtga

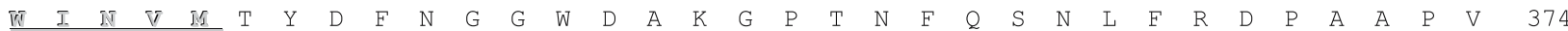

1189 ccggagatcgcgtttactacaatgtggacgactcgatccagaccttggtcaaggccggcgtgcccaagaccaagctgaacgtgggcatcccgttctatg

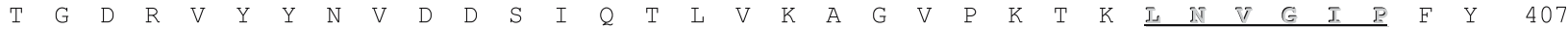

1288 gacgcggctgggccggcgtggcggctggacccaagggcgatggcttgtaccaggtggccaccggcgcgggcaaaggcacttacgaagccggcattgagg

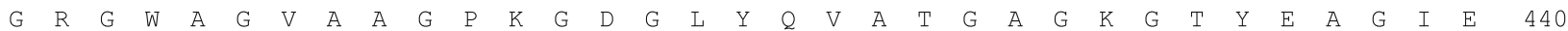

1387 actacaaagtgctgaaaacccgctccgccaagcagtttgtgcacccagtgagcaagcagctgtggacttacgacggcaacgagttctggagctatgacg

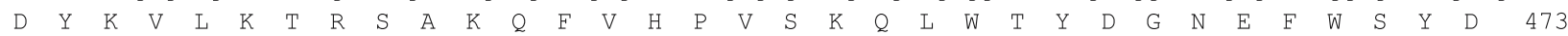

1486 accctgccaccatccgcaccaagctggactatgtgcgtcaacaacagctgggcggggtgttcagctggtccttggatggcgacgacgcccagggctcct

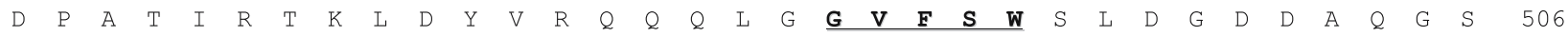

1585 tgctgaagaccaccagcgaagtgcgtcaggatgccgccgcggccaagaagaaggcggcggccaagacctcggccgcatcgccgctgaagtaagccggca

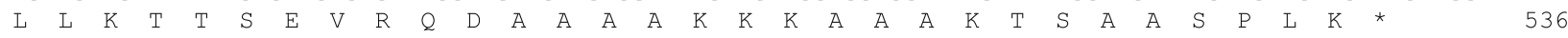

1684 gccgctatagagacgccgccgggcatgccoggcggtttttgtttaagagtgtgtttacgatttcgctcttgctcgtgagatcgtaaacaggttcttaca

1783 acagcacgcgttcgatgcccccgtcacgcgcttgctccacgtactgcttcaaccaatccgggcccagtacatgcttggcgatttccaccacaatgtagt

Fig. 4 Nucleotide and deduced amino acid sequence of chi54. The putative ribosome-binding site (aggagg) is boxed. The deduced amino acid sequence is given below the nucleotide sequence. The signal peptide cleavage site is shown by arrow $(\uparrow)$. The putative ChtBD3

Mutational analysis of conserved or nonconserved residues in CatDs of Chi54

The CatDs of Chi54 and other bacterial chitinases were first classified as subfamily A or B (Suzuki et al. 1999) (CHROMA format of the SMART program), and then further aligned as proposed by van Aalten et al. (2000). Chi54 has a CatD of a typical subfamily A. These have been divided into three subfamilies; subfamily A with an $\alpha+\beta$ insertion domain between $\beta 7$ and $\beta 8$ and subfamilies B and C without it (Suzuki et al. 1999). Subfamilies A and $\mathrm{B}$ can be easily distinguished by the length of the amino acid residues between $\beta 7$ and $\beta 8$ as shown in Figs. 4 and 6 . The location of $\beta$ strands are shown in Fig. 4. CatDs of subfamily A were found in chitinases from viruses, bacteria, fungi, insects, crustaceans, nematodes, entamoeba, and plants. Perfectly or highly conserved residues were observed around each $\beta$ strand in spite of diverse overall sequences in the genes. is boxed and the $\beta$-strands of the catalytic domain are in bold and underlined. The inverted repeat sequence is indicated by facing arrows

In this study, six perfectly conserved residues, two highly conserved residues and five nonconserved residues in $\beta 3, \beta 4$, $\beta 7$, and $\beta 8$ regions were mutated to other amino acid residues. The nonconserved residues modified were T218 of $\beta 3$, I270 of $\beta 4, N 401$ of $\beta 7$, and V493 and S497 of $\beta 8$. As the position of T218 had T, Y, S, A, N, G, R, or I in other naturally occurring chitinases, it was replaced with S (T218S). The I270 consisting of I, L, V, M, or F was replaced with L (I270L) or V (I270V). Similar processes were used for other mutations, i.e., N401V, V493M, and S497E (Fig. 7).

Cytoplasmic extracts from each of the mutant strains were analyzed by SDS-PAGE. Silver nitrate-stained gels showed that a protein of $54 \mathrm{kDa}$, which is identical to the chitinolytic enzymes produced by strain C-61, is produced in the wild type and 12 of the mutants. Strains expressing mutants of perfectly conserved residues (G216E, D271E, E273W, G403E, G492E, and W496E) and highly conserved residues (S213E and G215E) were unable to clear colloidal chitin on $1 / 2$ LB agar plates or in overlays of proteins separated on 

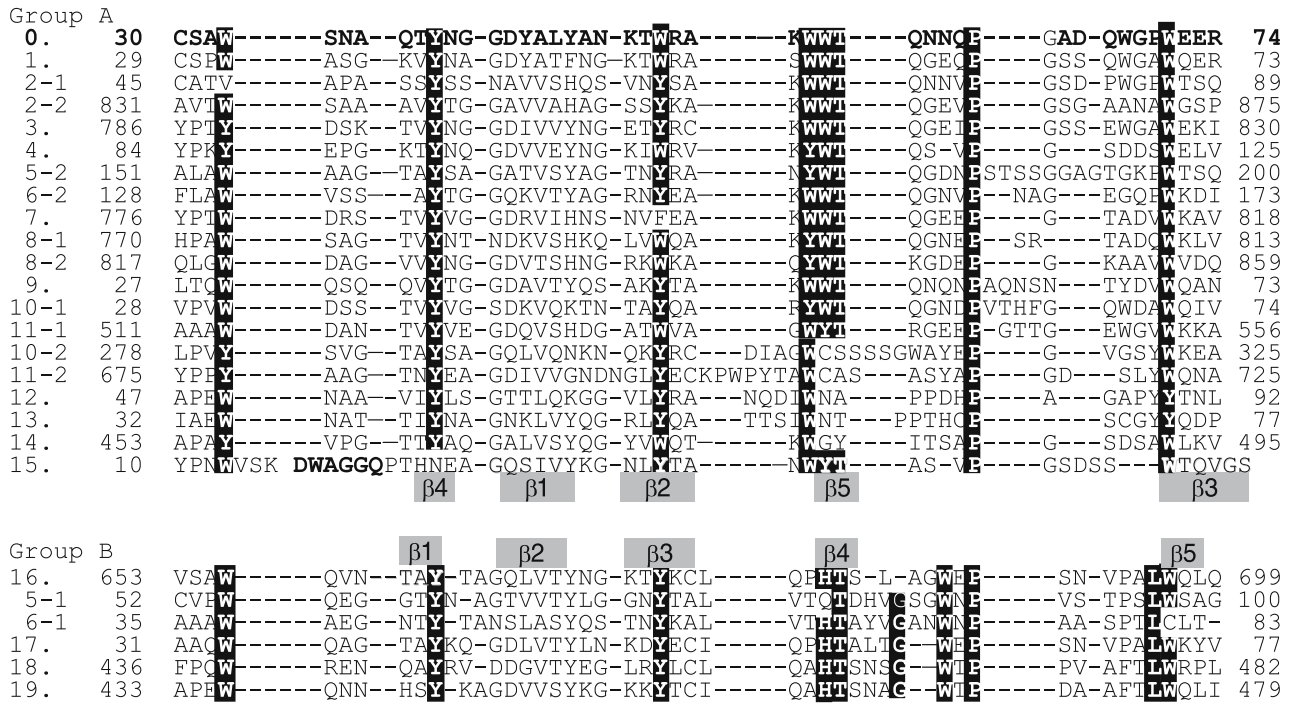

Fig. 5 Sequence alignment of the putative ChtBD3 of Chi54 and other bacterial chitinases. The sequences were aligned on the basis of $\mathrm{CBD}_{\mathrm{EGZ}}$ (row 15) and ChtBD $\mathrm{ChiAl}_{\text {( }}$ (row 16). The black backgrounds are amino acids well conserved in each group. The numbers at the left and right of each sequence represent the first and last residue positions in the chitinase, respectively. The -1 and -2 in the same numbers indicate the first and second ChtBD3 in the chitinase. Row: 0, Chi54 (Q5MYT4) of Chromobacterium sp.; 1, probable chitinase (Q7NQA0) from C. violaceum; 2, ChitiA (Q9RMB8) of Arthrobacter sp.; 3, ChiB (O50076) of Clostridium paraputrificum; 4, Pk-chiA (Q9UWR7) of Pyrococcus kodakaraensis; 5, Chi 69 (Q48373) of Jathinobacterium lividum; 6, Chi67 (Q9RCG5) of Doohwaniella chitinasigens; 7, ChiA (P32823) of Alteromonas sp.; 8, Chi92 (Q9F9Q8) of Aeromonas hydrophila; 9, ChiC (O50590) of Alteromonas sp.; 10, ChiA (Q9ZFP7) of Vibrio cholerae; 11, ChiA (P96168) of V. harveyi; 12, ChiA (O30678) of Xanthomonas maltophilia; 13, ChiA (Q9Z493) of Xanthomonas sp.; 14, ChiB (P11797) of Serratia marcescens; 15, CelZ (P07103) of Dickeya chrysanthemi; 16, ChiA1 (P20533) of Bacillus circulans; 17, ChiD (P27050) of B. circulans; 18, ChiC (Q9I1H5) of Pseudomonas aeruginosa; 19, ChiC (Q9WXD3) of S. marcescens

(Fig. 9). The purification, based on isoelectric point, was conducted in a Rotofor cell. The SDS-PAGE results show that the culture supernatants of recombinant E. coli and acidic fractions contain various proteins, while alkali fractions 19-20 contain only Chi54, including the typical active product of $52 \mathrm{kDa}$ which is always observed whenever the gene is expressed in C-61 or E. coli (Fig. 9a). The relative amount of the 52-kDa protein could be altered by cultural conditions; for example, it was relatively less abundant early in the cultural cycle, which suggests that it arose from secondary proteolysis of the secreted 54-kDa protein.

The kinetic parameters of the purified chitinases were determined with 4-MU-(GlcNAc) 2 (Table 2). The $K_{\mathrm{m}}$ values of the mutant enzymes were slightly changed, as would be expected as the binding domains were not altered (Table 2). However, $K_{\text {cat }}$ was substantially altered by the changes in the catalytic domains (Table 2). Mutant T218S had higher specific activities than Chi54 against synthetic methylumbelliferyl and chitin substrates, based on total relative activity (Table 3 ). With the purified enzymes, this mutant had 138,157 , and $147 \%$ of the activity of the native Chi54 against the synthetic substrate, colloidal chitin, and native chitin, respectively, which is in agreement with the increase in activity measured with nonpurified culture
To determine specific activity of the $54-\mathrm{kDa}$ protein, the chitinases of the wild type and six mutants were purified
Purification and properties of Chi54 and its mutated proteins 

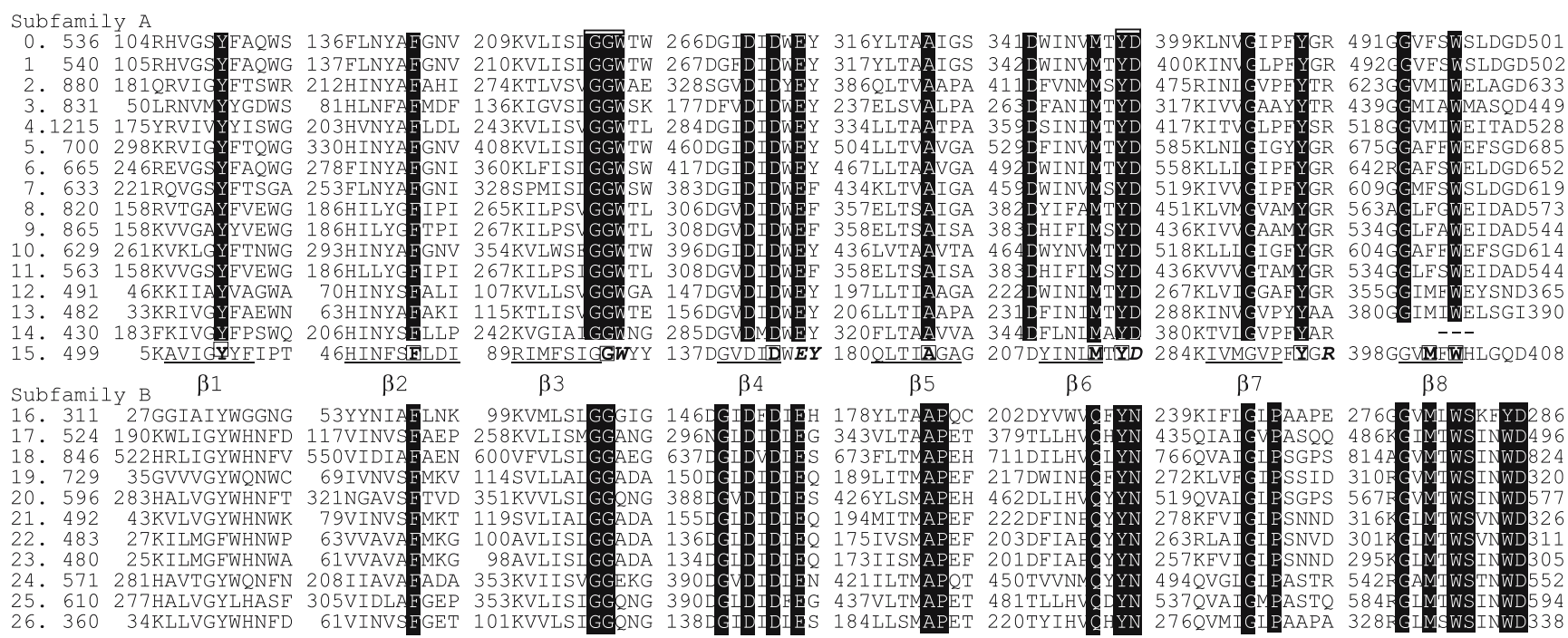

Fig. 6 Sequence alignment of the putative catalytic domain of Chi54 and family 18 chitinases. The sequences were aligned on the basis of the strands $\beta 1-\beta 8$ of ChiB from $S$. marcescens (row 15), in which bold letters in boxes indicate the -1 subsites and bold letters with italics indicate the +1 subsites. The black backgrounds are amino acids well conserved in each subfamily. The numbers next to the row numbers represent total amino acids of the protein. The numbers at the left of each sequence represent the residue positions in the protein. Row: 0, Chi54 (Q5MYT4) of Chromobacterium sp.; 1, probable chitinase (Q7NQA0) from C. violaceum; 2, ChitiA (Q9RMB8) of Arthrobacter sp.; 3, ChiB (O50076) of C. paraputrificum; 4, Pk-chiA (Q9UWR7) of P. kodakaraensis; 5, ChiA (O30678) of X. maltophilia; 6, Chi 69 (Q48373) of J. lividum; 7,

supernatants (Fig. 9). Mutant N401V was similar in activity relative to Chi54. On the other hand, mutants I270V, I270L, V493M, and S497E had lower activity than the native enzyme in all tests performed.

\section{Discussion}

The sequence of chi54 had $81 \%$ identity to GI:34499695 from C. violaceum. C. violaceum and C61 have 93\% identity in the $16 \mathrm{~S}$ ribosomal region, suggesting that it is similar to, but not congruent with, $C$. violaceum (Park et al. 2005). However, chi54 was less than $51 \%$ identical to other chitinases examined. Of the chitinases with a ChtBD and a CatD, the smallest protein was chitinase C (430aa) from Alteromonas sp., but it has a deletion in the $\beta 8$ region. Chitinase B (499aa) from Serratia marcescens had a ChtBD and a CatD but did not have a signal sequence. Some chitinases larger than Chi54 had more than one ChtBD and/or other domains in addition to a CatD. An archeonbacterial chitinase was reported to have three ChtBDs and two CatDs (Tanaka et al. 1999, 2001).

The secreted chitinase in both recombinant $E$. coli and wild type strain C-61 contained proteins of 54 and $52 \mathrm{kDa}$. The molecular size calculated from the deduced amino acid
Chi67 (Q9RCG5) of D. chitinasigens; 8, ChiA (P32823) of Alteromonas sp.; 9, Chi92 (Q9F9Q8) of A. hydrophila; 10, Chitinase C (Q9L8G0) of Streptomyces peucetius; 11, ChiA (P07254) of S. marcescens; 12, Chitinase C (P94289) of B. circulans; 13, ChiA (Q59326) of Clostridium thermocellum; 14, ChiC (O50590) of Alteromonas sp.; 15, ChiB (P11797) of $S$. marcescens; 16, HevamineA (P23472) of Hevea brasiliensis; 17, ChiD (P27050) of B. circulans; 18, ChiA (Q9ZFP7) of V. cholerae; 19, ChiA (P96168) of V. harveyi; 20, ChiA (Q9Z493) of Xanthomonas sp.; 21, ChiA (Q9CE95) of Lactococcus lactis; 22, ChiC (Q9I1H5) of P. aeruginosa; 23, ChiC (Q9WXD3) of S. marcescens; 24, ChiA (Q59924) of Streptomyces lividans; 25, ChiB (Q9S5K1) of S. coelicolor; 26, Chi36 (Q93QD3) of B. cereus

sequence of the mature protein was $55,102 \mathrm{Da}$. These data suggest that the secreted enzymes from both E. coli and C61 were proteolytically cleaved during processing to give the two molecular weights. Multiple chitinases from single genes have been detected in other systems. For example, a $35-\mathrm{kDa}$ chitinase from S.marcescens was obtained by cleavage of a 52-kDa chitinase (Gal et al. 1998) and a 56$\mathrm{kDa}$ chitinase from Janthinobacterium lividum was derived from a $69-\mathrm{kDa}$ chitinase (Gleave et al. 1995). The 59-kDa chitinase from Streptomyces olivaceoviridis was proteolytically processed to a $47-\mathrm{kDa}$ truncated chitinase lacking the chitin-binding domain (Blaak and Schrempf 1995).

The $\mathrm{pI}$ value of 8.67 that was predicted from the deduced amino composition was consistent with the measured $\mathrm{pI}$ of 8.7 by isoelectrofocusing in the previous experiments (Park et al. 2005). We calculated that the portable chitinase gene from C. violaceum ATCC 12472 had a pI value of 8.69. An alkaline $\mathrm{pI}$ in this range was not found with the other bacterial chitinases in searches of gene databases or the published literature. Segments of AAAAKKKAAAKTAAS in Chi54 and AAAAAAAKAKAAKK in the portable chitinase gene of $C$. violaceum ATCC 12472 were present at the C-terminal region. Such segments were observed in other basic proteins but were not observed in other chitinases. If these sequences were excluded from calcula- 


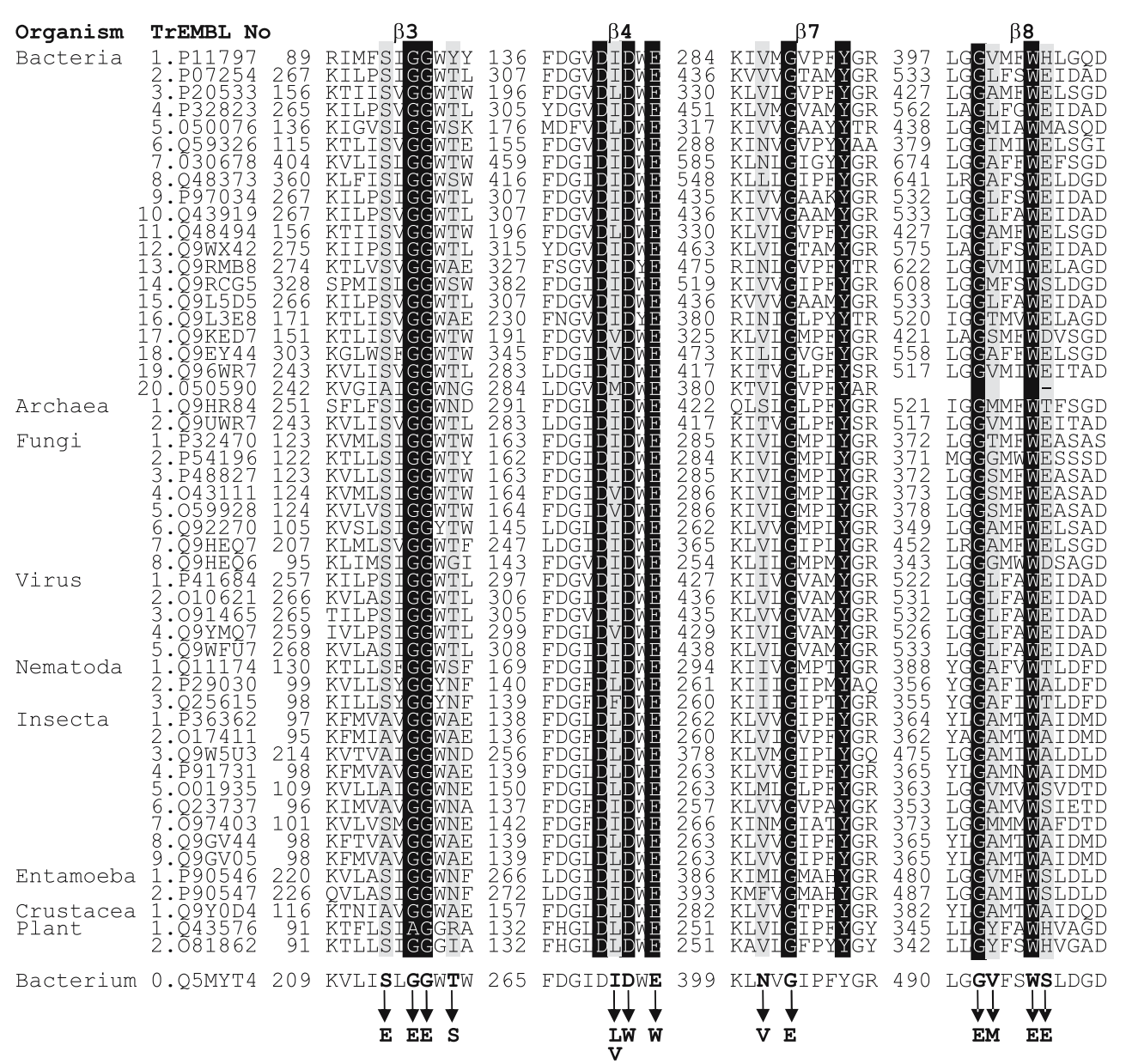

Fig. 7 Target amino acid residues of Chi54 for site-directed mutagenesis. Conserved (black background) and nonconserved (grey background) amino acid residues in family 18 chitinases with CatD of

subfamily A. The sequences were aligned on the basis of the strands $\beta 1-\beta 8$ of ChiB from $S$. marcescens (P11797). The numbers at the left of each sequence represent the residue positions in the protein

tion of pI values, the remainder of the protein was calculated to have a pI of 7.71 for Chi54 and 6.37 for a C. violaceum chitinase which suggests that this sequence is responsible for the basic pI of Chi54.

Chi54 bound tightly to chitin but less well to cellulose. It had a ChtBD of type 3 (ChtBD3); the ChtBD3s are usually contained in bacterial chitinases (Henrissat 1999). ChiBD3s with a stWWst motif have been subclassified as Group A and without the motif as Group B (Hashimoto et al. 2000; Ikegami et al. 2000). The ChtBD3 of Chi54 contains a typical stWWst motif. However, Chi54 lacks the DWAGGQ loop found in $\mathrm{CBD}_{\mathrm{Cel} 5}$ (formerly known as $\mathrm{CBD}_{\mathrm{EGZ}}$ ). This loop appears to be important for binding affinity to cellulose, as $\mathrm{CBD}_{\mathrm{EGZ}}$ has about ten times higher binding affinity to cellulose than to chitin (Simpson and Barras 1999), while ones without this region bind less tightly to cellulose. For example, chitinase $\mathrm{C}$ from Alteromonas sp. strain O-7 bound to both chitin and cellulose, but affinities for the substrates were about equal, in contrast to enzymes with the loop (Tsujibo et al. 1998). Chitinase B from Clostridium paraputrificum showed significant affinity for cellulose
(Morimoto et al. 1997) even though these lack the DWAGGQ loop. However, like Chi54, they do contain the stWWst motif that may also be involved in binding to both substrates. Larger chitinases had generally one or more ChtBDs and/or other domains in addition to a CatD. From this analysis, it is clear that small changes in the chitinbinding domains of these enzymes may rather dramatically change the binding, and potentially the functionality, of chitinases. Experiments are underway to elucidate the structure-function relationships within these chitin-binding domains.

A major portion of this research dealt with the elucidation of the structure-function relationships in the catalytic domain (CatD) of Chi54. Alignments of family 18 chitinases have been described (van Aalten et al. 2000; Lu et al. 2002; Papanikolau et al. 2001; Suginta et al. 2005; Synstad et al. 2004; Thomas et al. 2000). Recently, the family 18 chitinases were suggested to subdivide into two functional subgroups; the chitinase group and the hevamine group (Bokma et al. 2002). Residue $F$ of $\beta 2$, GG of $\beta 3$, $\operatorname{DxDxE}$ of $\beta 4$, A of $\beta 5$, Y of $\beta 6, \mathrm{G}$ of $\beta 7$, and GxxxW of 
Fig. 8 Comparison of E. coli strains harboring a chi54 and its mutated chi54. a Chitinolytic abilities of the strains grown for 5 days at $37^{\circ} \mathrm{C}$ on $1 / 2$ LB plates containing colloidal chitin. b Chitinase activities of cytoplasmic fractions of cells cultured for 1 day in TB broth and culture supernatants cultured for 5 days in $1 / 2$ LB containing colloidal chitin. c Silver staining after SDS-PAGE with cytoplasmic fractions. d Chitinolytic zymography after SDS-PAGE with cytoplasmic fractions. Numbers $1-15$ indicate Chi54, S213E, G215E, G216E, T218S, I270V, I270L, D271W, E273W, N401V, G403E, G492E, V493M, S497E, and W496E, respectively
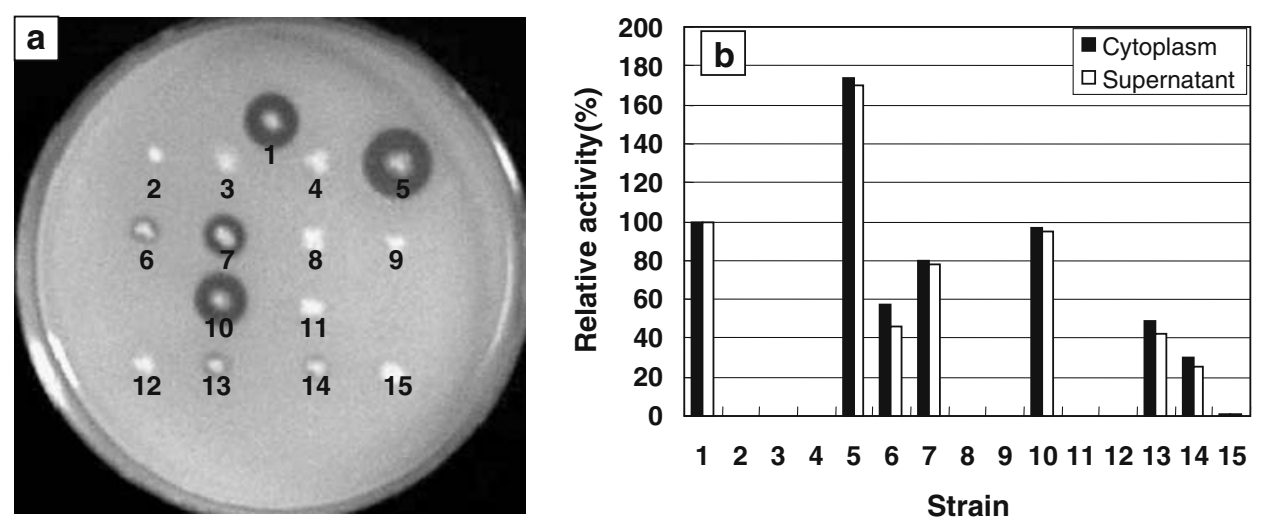

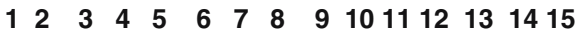
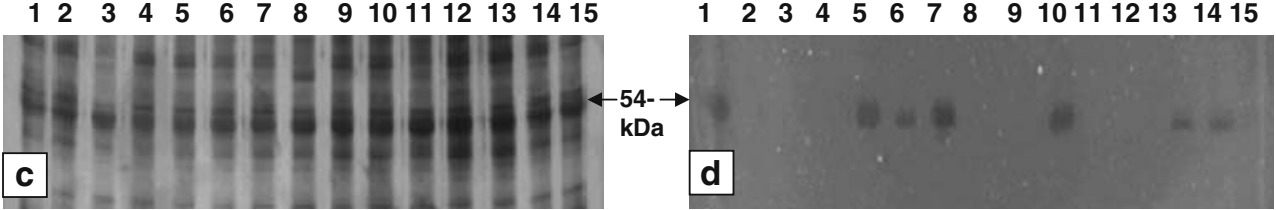

$\beta 8$ were conserved in both subfamilies A and B. However, the other conserved residues were different from subfamily $A$ and subfamily $B$; for example, MxYD of $\beta 6$ region in subfamily A consisted of QxYN in subfamily B. Of a total of ten residues reported as the -1 subsites in the ChiB from $S$. marcescens (van Aalten et al. 2000), nine residues (Y of $\beta 1, F$ of $\beta 2, G$ of $\beta 3, D$ of $\beta 4, A$ of $\beta 5, M x Y$ of $\beta 6, Y$ of $\beta 7$, and $W$ of $\beta 8$ ) were conserved in subfamily $A$, but only one residue ( $\mathrm{M}$ of $\beta 8$ ) was conserved in subfamily $\mathrm{B}$. On the other hand, $Y$ of $\beta 1, M$ of $\beta 6$, and $Y$ of $\beta 7$ were not conserved in subfamily $\mathrm{B}$. As the CatD of ChiB belongs to subfamily $A$, the -1 subsites may be in better agreement with the residues conserved in subfamily $A$ than in subfamily B. From these observations, we suggest that sequence alignment of the family 18 CatD must be compared with members of the same subfamily, because some conserved residues are different from subfamily A and subfamily B.
Several residues of chitinases including G216 of $\beta 3$, D271 and E273 of $\beta 4$, G403 of $\beta 7$, and G492 and W496 of $\beta 8$ are identical in all chitinases examined. Mutational insertion of alternative amino acids at any of these sites resulted in a loss of almost all activity, which demonstrates that they are essential for enzyme function. For example, substitution of $\mathrm{E}$ for $\mathrm{G} 215$ resulted in almost total loss of activity, as also was the case with G216. These results are similar to those from studies with Chi85 from Alteromonas sp. in which G251P and G251V mutants had very low activity. In the $\beta 4$ region, mutational analysis of the DxDxE motif, which is perfectly conserved, has been conducted in several chitinases. In this study, substitution at any of these sites (D271W or E273W) resulted in greatly reduced or total elimination of activity. In the $A$. caviae chitinase, nearly all activity was lost by the mutation from aspartate to glutamate (D313E) but considerable activity remained after the mutation to asparagine (D313N) (Lin et al. 1999).
Fig. 9 One-step purification of Chi54 and its mutated chitinases. a Silver staining after SDS-PAGE with culture supernatant of recombinant $E$. coli (lane 0 ) and samples obtained in each fraction of the Rotofor cell (lanes 6-20). b Silver staining after SDS-PAGE with samples obtained in fractions 18-20, where lanes $1-7$ indicate proteins of Chi54, T218S, I270V, I270L, N401V, V493M, and S497E, respectively, and $M$ indicates the molecular weight marker

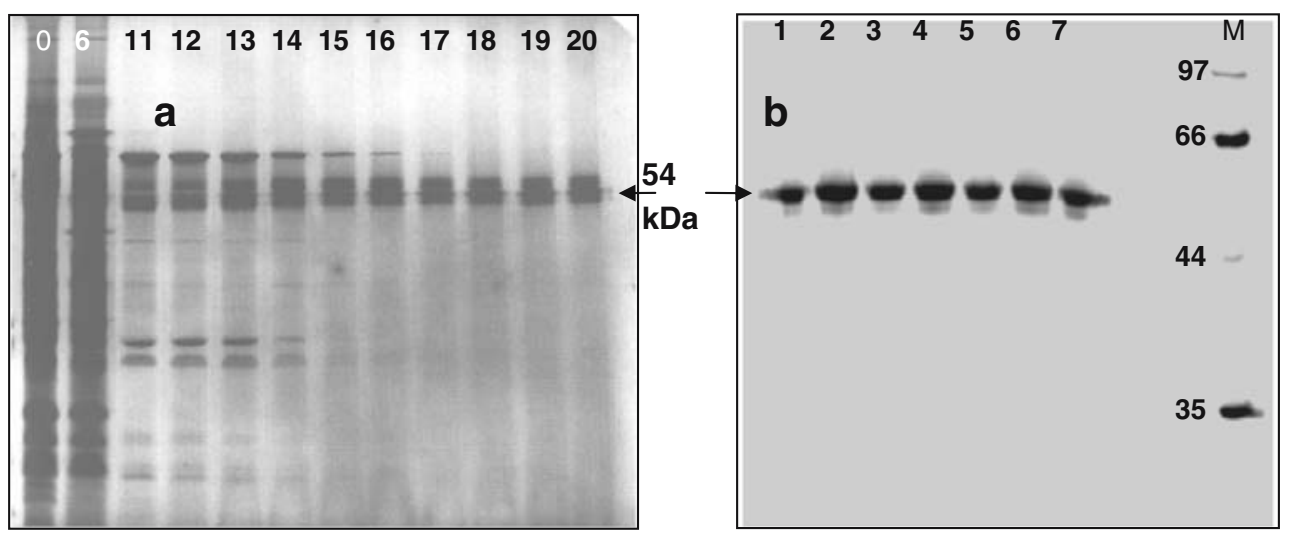


Table 2 Kinetic parameters of Chi54 and its mutated chitinases measured with 4-MU-(GlcNAc) $)_{2}$ as the substrate

\begin{tabular}{lllll}
\hline Enzyme & $K_{\mathrm{m}}(\mu \mathrm{M})$ & $K_{\text {cat }}\left(\mathrm{S}^{-1}\right)$ & $K_{\text {cat }} / K_{\mathrm{m}}$ & $\begin{array}{l}\text { Relative } \% \\
K_{\text {cat }} / K_{\mathrm{m}}\end{array}$ \\
\hline Chi54 & $36 \pm 3.2$ & $18 \pm 2.0$ & $0.49 \pm 0.05$ & 100 \\
T218S & $34 \pm 7.7$ & $24 \pm 1.3$ & $0.70 \pm 0.07$ & $143 \pm 10$ \\
I270V & $35 \pm 2.0$ & $9 \pm 0.5$ & $0.27 \pm 0.02$ & $55 \pm 4$ \\
I270L & $36 \pm 2.9$ & $13 \pm 1.3$ & $0.35 \pm 0.02$ & $71 \pm 10$ \\
N401V & $42 \pm 2.9$ & $20 \pm 1.8$ & $0.47 \pm 0.08$ & $98 \pm 19$ \\
V493M & $36 \pm 2.4$ & $9 \pm 0.7$ & $0.23 \pm 0.04$ & $48 \pm 7$ \\
S497E & $35 \pm 2.5$ & $7 \pm 0.7$ & $0.19 \pm 0.04$ & $40 \pm 7$ \\
\hline
\end{tabular}

Numbers followed by \pm represent the averages and standard deviations measured over three experiments.

Conversely, Alteromonas sp. Chi85 lost nearly all activity in the mutation to asparagine (D290N) but retained considerable activity in the mutation to glutamate (D290E) (Tsujibo et al. 1993). Further, mutation of the homologous E273 by substitution with aspartic acid, glutamine, alanine, or glycine in other studies (Lin et al. 1999; Lu et al. 2002; Papanikolau et al. 2001; Synstad et al. 2004; Thomas et al. 2000; Tsujibo et al. 1993; Watanabe et al. 1993) led to inactivation. Finally, in this study, mutation within the $\beta 7$ and $\beta 8$ region-G403E, G492E, or W496E-resulted in loss of almost all activity. In a similar study, mutation W496A of chitinase A1 from Bacillus circulans WL-12 resulted in a loss of almost all activity (Watanabe et al. 2003).

However, at other sites, amino acids are imperfectly conserved and in this study, substitution for several of these was less detrimental than substitution of the fully conserved amino acids. In the $\beta 3$ region, S213 or its homologue contains serine in most chitinases, but in most insect chitinases, the residue was alanine. Chi54 contains serine in this site, its substitution by alanine somewhat reduced activity (data not shown), but a mutation to the acidic amino acid glutamate greatly reduced activity. In other studies, mutation of S213 to alanine retained considerable

Table 3 Relative activity (\%) of Chi54 and its mutated chitinases measured with various substrates

\begin{tabular}{llll}
\hline Enzyme & 4-MU-(GlcNAc) & Colloidal chitin & Crystal chitin \\
\hline Chi54 & 100 & 100 & 100 \\
T218S & $138 \pm 11.2$ & $157 \pm 20.5$ & $147 \pm 15.8$ \\
I270V & $52 \pm 5.3$ & $49 \pm 6.0$ & $67 \pm 7.1$ \\
I270L & $67 \pm 3.5$ & $69 \pm 5.7$ & $74 \pm 6.2$ \\
N401V & $98 \pm 11.6$ & $102 \pm 14.2$ & $100 \pm 11.3$ \\
V493M & $49 \pm 4.3$ & $48 \pm 5.2$ & $65 \pm 6.2$ \\
S497E & $39 \pm 2.5$ & $42 \pm 5.8$ & $59 \pm 5.8$ \\
\hline
\end{tabular}

Numbers followed by \pm represent the averages and standard deviations measured over three experiments. activities in B. circulans WL-12 ChiA1 (Watanabe et al. 1993) and Serratia marcescens ChiB (Synstad et al. 2004), but nearly all activity was lost in Alteromonas sp. Chi85 (Tsujibo et al. 1993). Of six mutants, one mutant (T218S) had higher activity than Chi54, and another mutant (N401V) retained similar activity, while four mutants (I270L, I270V, V493M, S497E) showed lower activity. These indicate that the nonconserved residues are less critical for catalysis, although variation of chitinase activity occurs by their mutation.

One mutant, T218S, is of practical interest as this modified protein had higher activity against synthetic substrates and soluble and insoluble chitin than Chi54, with the level of activity being $170 \%$ of the native Chi54. This increase in activity is expected to provide substantially improved biocontrol and capabilities in industrial processes described in the introduction to this paper. This is in contrast to a mutant of chitinase A1 from Bacillus circulans WL-12, where activity against synthetic substrates was reported to increase by point mutation, but activity against colloidal chitin and crystal chitin decreased (Hashimoto et al. 2000).

This study also indicates very practical methods for further improvement of the activities of this enzyme for various uses. The substantial increase observed by the mutation T218S clearly is only the starting point for further improvements that are possible.

In addition, this study provides a simple method for producing pure chitinase by single step purification after production in E. coli. Taken together, the potential for producing mutant chitinases with improved activity or alterations of binding sites for particular applications, plus simple production and purification processes, is of substantial potential value.

Acknowledgements This study was supported by the Technology Development Program for Agricultural and Forestry, Ministry of Agriculture and Forestry, Republic of Korea. The authors thank Kristen Ondik and Michal Shoresh for editorial assistance.

\section{References}

Blaak H, Schrempf H (1995) Binding and substrate specificities of a Streptomyces olivaceoviridis chitinase in comparison with its proteolytically processed form. Eur J Biochem 229:132-139

Bokma E, Rozeboom HJ, Sibbald M, Dijkstra BW, Beintema JJ (2002) Expression and characterization of active site mutants of hevamine, a chitinase from the rubber tree Hevea brasiliensis. Eur J Biochem 269:893-901

Bolar JP, Norelli JL, Harman GE, Brown SK, Aldwinckle HS (2001) Synergistic activity of endochitinase and exochitinase from Trichoderma atroviride (T. harzianum) against the pathogenic fungus (Venturia inaequalis) in transgenic apple plants. Transgenic Res 10:533-543 
Broadway RM, Williams DL, Kain WC, Harman GE, Lorito M, Labeda DP (1995) Partial characterization of chitinolytic enzymes from Streptomyces albidoflavus. Lett Appl Microbiol 20:271-276

Broadway R, Gongora C, Kain WC, Sanderson JP, Monroy JA, Bennett KC, Warner JB, Hoffman MP (1998) Novel chitinolytic enzymes with biological activity against herbivorous insects. J Chem Ecol 24:985-998

Brun E, Moriaud F, Gans P, Blackledge MJ, Barras F, Marion D (1997) Solution structure of the cellulose-binding domain of the endoglucanase $\mathrm{Z}$ secreted by Erwinia chrysanthemi. Biochemistry 36:16074-16086

Chernin L, Ismailov Z, Haran S, Chet I (1995) Chitinolytic Enterobacter agglomerans antagonistic to fungal plant pathogens. Appl Environ Microbiol 61:1720-1726

Ding X, Gopalakrishnan B, Johnson JB, White FF, Wang X, Morgan TD, Kramer KJ, Muthukrishnan S (1998) Insect resistance of transgenic tobacco expressing an insect chitinase gene. Transgenic Res 7:77-84

Fang W, Leng B, Xiao Y, Jin K, Ma J, Fan Y, Feng J, Yang X, Zhang Y, Pei Y (2005) Cloning of Beauveria bassiana chitinase gene Bbchit1 and its application to improve fungal strain virulence. Appl Environ Microbiol 71:363-370

Flach J, Pilet PE, Jolles P (1992) What's new in chitinase research? Experientia 48:701-716

Gal SW, Choi JY, Kim CY, Cheong YH, Choi YJ, Lee SY, Bahk JD, Cho MJ (1998) Cloning of the 52-kDa chitinase gene from Serratia marcescens KCTC2172 and its proteolytic cleavage into an active 35-kDa enzyme. FEMS Microbiol Lett 160:151-158

Gilkes NR, Henrissat B, Kilburn DG, Miller RC Jr, Warren RA (1991) Domains in microbial $\beta$-1,4-glycanases; sequence conservation, function, and enzyme families. Microbiol Rev $55: 303-315$

Gleave AP, Taylor RK, Morris BA, Greenwood DR (1995) Cloning and sequencing of a gene encoding the 69-kDa extracellular chitinase of Janthinobacterium lividum. FEMS Microbiol Lett 131:279-288

Hashimoto M, Ikegami T, Seino S, Ohuchi N, Fukada H, Sugiyama J, Shirakawa M, Watanabe T (2000) Expression and characterization of the chitin-binding domain of chitinase A1 from Bacillus circulans WL-12. J Bacteriol 182:3045-3054

Henrissat B (1999) Classification of chitinases modules. In: Jolles P, Muzzarelli RAA (eds) In Chitin and Chitinases. Birkhauser Verlag, Basel (1999), pp 137-156

Henrissat B, Davies G (1997) Structural and sequence-based classification of glycoside hydrolases. Curr Opin Struct Biol 7:637644

Ikegami T, Okada T, Hashimoto M, Seino S, Watanabe T, Shirakawa M (2000) Solution structure of the chitin-binding domain of Bacillus circulans WL-12 chitinase A1. J Biol Chem 275:13654-13661

Jeuniaux C (1966) Chitinases. Methods Enzymol 8:644-650

Kawase T, Saito A, Sato T, Kanai R, Fujii T, Nikaidou N, Miyashita K, Watanabe T (2004) Distribution and phylogenetic analysis of family 19 chitinases in Actinobacteria. Appl Environ Microbiol 70:1135-1144

Kobayashi DY, Reedy RM, Bick J, Oudemans PV (2002) Characterization of a chitinase from Stenotrophomonas maltophilia. Strain $34 \mathrm{~S} 1$ and its involvement in biological control. Appl Environ Microbiol 68:1047-1054

Laemmli UK (1970) Cleavage of structural proteins during the assembly of the head of bacteriophage T4. Nature (London) 227:680-685

Lin FP, Chen HC, Lin CS (1999) Site-directed mutagenesis of Asp313, Glu315, and Asp391 residues in chitinase of Aeromonas caviae. IUBMB Life 48:199-204

Lorito M, Harman GE, Hayes CK, Broadway RM, Tronsmo A, Woo SL, DiPietro A (1993) Chitinolytic enzymes produced by
Trichoderma harzianum: antifungal activity of purified endochitinase and chitobiosadase. Phytopathology 83:302-307

Lu Y, Zen KC, Muthukrishnan S, Kramer KJ (2002) Site-directed mutagenesis and functional analysis of active site acidic amino acid residues D142, D144 and E146 in Manduca sexta (tobacco hornworm) chitinase. Insect Biochem Mol Biol 32:1369-1382

McGrew BR, Green DM (1990) Enhanced removal of detergent and recovery of enzymatic activity following sodium dodecyl sulfatepolyacrylamide gel electrophoresis: use of casein in gel wash buffer. Anal Biochem 189:68-74

Morimoto K, Karita S, Kimura T, Sakka K, Ohmiya K (1997) Cloning, sequencing, and expression of the gene encoding Clostridium paraputrificum chitinase $\mathrm{ChiB}$ and analysis of the functions of novel cadherin-like domains and a chitin-binding domain. J Bacteriol 179:7306-7314

Papanikolau Y, Prag G, Tavlas G, Vorgias CE, Oppenheim AB, Petratos K (2001) High resolution structural analyses of mutant chitinase A complexes with substrates provide new insight into the mechanism of catalysis. Biochemistry 40:11338-11343

Park SK, Lee HY, Kim KC (1995a) Antagonistic effect of chitinolytic bacteria on soilborne plant pathogens. Korean J Plant Pathol $11: 47-52$

Park SK, Lee HY, Huh JW (1995b) Production and some properties of chitinolytic enzymes by antagonistic bacteria. Korean J Plant Pathol 11:258-264

Park SK, Lee HY, Kim KC (1995c) Role of chitinase produced by Chromobacterium violaceum in the suppression of Rhizoctonia damping-off. Korean J Plant Pathol 11:304-311

Park SK, Lee MC, Harman ME (2005) The biocontrol activity of Chromobacterium sp. strain C-62 against Rhizoctonia solani depends on the productive ability of chitinase. Korean J Plant Pathol 21:275-282

Sambrook J, Fritsch EF, Maniatis T (1989) Molecular cloning: a laboratory manual, 2nd edn. Cold Spring Harbor Laboratory, Cold Spring Harbor

Shapiro M, Preisler HK, Robertson JL (1987) Enhancement of baculovirus activity of on gypsy moth (Lepidoptera; Lymantriidae) by chitinases. J Econ Entomol 80:1113-1116

Simpson HD, Barras F (1999) Functional analysis of the carbohydrate-binding domains of Erwinia chrysanthemi Cel5 (Endoglucanase Z) and an Escherichia coli putative chitinase. J Bacteriol 181:4611-4616

Simpson PJ, Xie H, Bolam DN, Gilbert HJ, Williamson MP (2000) The structural basis for the ligand specificity of family 2 carbohydrate-binding modules. J Biol Chem 275:41137-41142

Suginta W, Vongsuwan A, Songsiriritthigul C, Svasti J, Prinz H (2005) Enzymatic properties of wild-type and active site mutants of chitinase A from Vibrio carchariae, as revealed by HPLC-MS. FEBS J 272:3376-3386

Suzuki K, Taiyoji M, Sugawara N, Nikaidou N, Henrissat H, Watanabe T (1999) The third chitinase gene (chiC) of Serratia marcescens 2170 and the relationship of its product to other bacterial chitinases. Biochem J 343:587-596

Synstad B, Gaseidnes S, van Aalten DM, Vriend G, Nielsen JE, Eijsink VG (2004) Mutational and computational analysis of the role of conserved residues in the active site of a family 18 chitinase. Eur J Biochem 271:253-262

Tanaka T, Fujiwara S, Nishikori S, Fukui T, Takagi M, Imanaka T (1999) A unique chitinase with dual active sites and triple substrate binding sites from the hyperthermophilic archaeon Pyrococcus kodakaraensis KOD1. Appl Environ Microbiol 65:5338-5344

Tanaka T, Fukui T, Imanaka T (2001) Different cleavage specificities of the dual catalytic domains in chitinase from the hyperthermophilic archaeon Thermococcus kodakaraensis KOD1. J Biol Chem 276:35629-35635 
Thomas CJ, Gooday GW, King LA, Possee RD (2000) Mutagenesis of the active site coding region of the Autographa californica nucleopolyhedrovirus chiA gene. J Gen Virol 81:1403-1411

Tronsmo A, Harman GE (1993) Detection and quantification of $\mathrm{N}$ acetyl- $\beta$-D-glucosaminidase, chitobiosidase and endochitinase in solutions and on gels. Anal Biochem 208:74-79

Trudel J, Asselin A (1989) Detection of chitinase deacetylase activity after polyacrylamide gel electrophoresis. Anal Biochem 189:249-253

Tsujibo H, Orikoshi H, Imada C, Okami Y, Miyamoto K, Inamori Y (1993) Site-directed mutagenesis of chitinase from Alteromonas sp. strain O-7. Biosci Biotechnol Biochem 57:1396-1407

Tsujibo H, Orikoshi H, Shiotani K, Hayashi M, Umeda J, Miyamoto K, Imada C, Okami Y, Inamori Y (1998) Characterization of chitinase $\mathrm{C}$ from a marine bacterium, Altermonas sp. strain $\mathrm{O}-7$, and its corresponding gene and domain structure. Appl Environ Microbiol 64:472-478

van Aalten DM, Synstad B, Brurberg MB, Hough E, Riise BW, Eijsink VG, Wierenga RK (2000) Structure of a two-domain chitotriosidase from Serratia marcescens at 1.9-^̊ resolution. Proc Natl Acad Sci U S A 97:5842-5847

Watanabe T, Kobori K, Miyashita K, Fujii T, Sakai H, Uchida M, Tanaka H (1993) Identification of glutamic acid 204 and aspartic 200 in chitinase A1 of Bacillus circulans WL-12 as essential residues for chitinase activity. J Biol Chem 268:18567-18572

Watanabe T, Ariga Y, Sato U, Toratani T, Hashimoto M, Nikaidou N, Kezuka Y, Nonaka T, Sugiyama J (2003) Aromatic residues within the substrate-binding cleft of Bacillus circulans chitinase A1 are essential for hydrolysis of crystalline chitin. Biochem J 376:237-244 